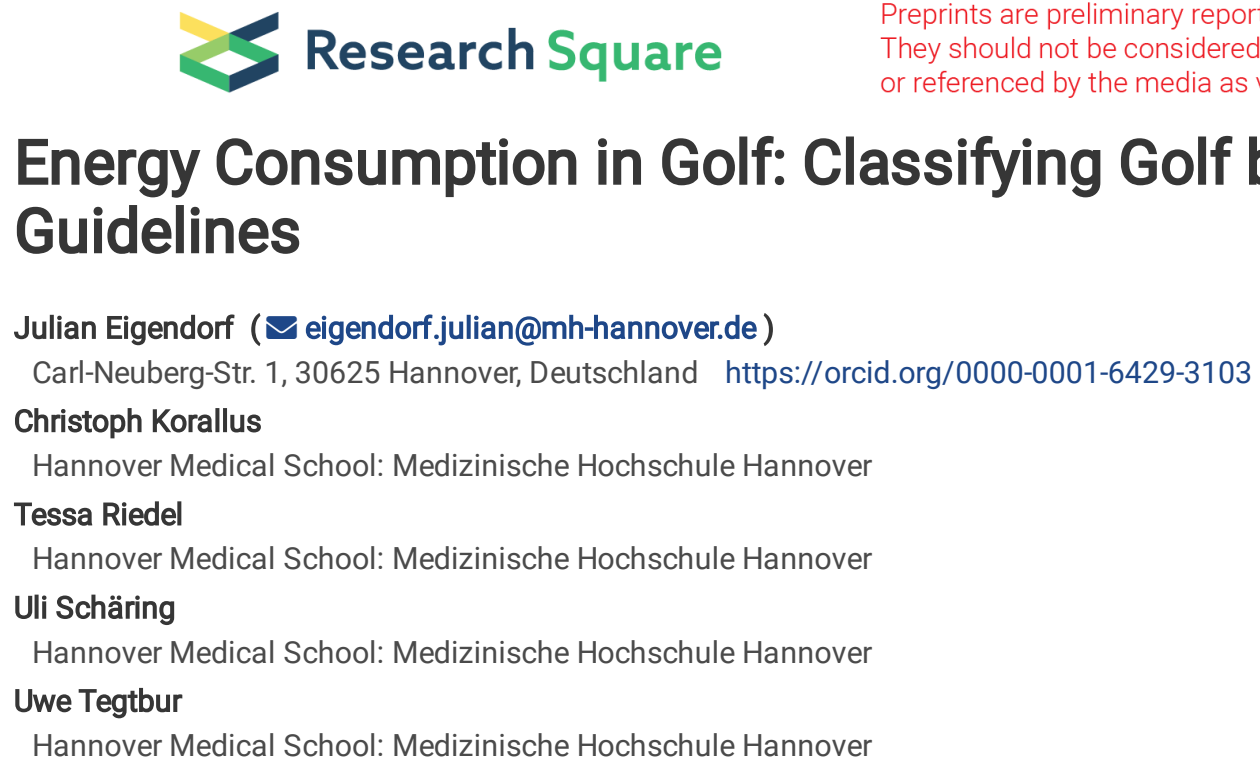

\title{
Energy Consumption in Golf: Classifying Golf by Physical Activity Guidelines
}




\section{Abstract}

Introduction: Physical activity is known to improve physical fitness and health. Playing Golf is a wide spread leisure time activity, but has yet to be evaluated in regard of energy consumption and physical stress. We conducted a cross-over design study with two groups of different age and skill level to evaluate energy consumption and relative stress and compared the results with intensity levels of physical activity guidelines.

Methods: We recruited 20 healthy, male subjects, 10 with a high skill level and 10 having a lower skill level. All subjects completed a graded exercise test (GXT), a golf practice session (each 5 strokes with 5 different clubs) and 9 holes of golf on two different days. During all testing sessions gas exchange data and heartrate was continuously captured with a mobile breathing gas analyzer.

Results: Exercise intensities (as proportion of $\mathrm{VO}_{2 \text { peak }}$ ) during practice were $34.2 \pm 6.5 \%$ in $\mathrm{LOW}$ and $36.4 \pm 6.5 \%$ in $\mathrm{HIGH}$. \% VO 2 peak while playing golf was $45.0 \pm 6.4 \%$ in LOW and $46.2 \pm 8.8 \%$ in HIGH. Mean METs during the 9 holes of golf were not significantly ( $p=0.596)$ different between groups LOW $(5.13 \pm 0.49)$ and $\mathrm{HIGH}(4.98 \pm 0.77)$.

Conclusion: The two groups showed neither during practice nor during playing golf significant differences in METs and \%VO2. Both groups reached moderate intensity with METs and \%VO2 according to the ACSM guidelines on the golf course but not on the driving range. The groups spent about half the time during playing 9 holes of golf in the "moderate" intensity category according to ACSM. Thus golf is a valid sport to improve physical fitness and cardiovascular risk factors.

\section{Introduction (Background)}

Structured exercise and physical activity are well known to not only improve physical fitness, but also alter various health parameters in a positive fashion. To yield health benefits, exercises need to meet certain characteristics e. g. specific levels of intensity or duration. Prolonged exercises with a moderate intensity are generally accepted as an effective mean to improve overall health $(1,2)$. Guidelines and recommendations for cardiorespiratory exercise to improve overall health are given by the World Health Organization (WHO), the American College of Sports Medicine (ACSM) and by the German Federal Ministry of Health(3-5). These groups agree on their recommendations for physical exercise to improve cardiovascular health in adults. The ACSM guidelines also categorize activities according to level of intensity (light, moderate and vigorous), as derived from the energy consumption during activity. Various sports are popular and acknowledged to elevate fitness and health levels, e. g. cycling, running, fitness or various team sports. However, in 2019 the German Golf Association (Deutscher Golf Verband, DGV) was the $8^{\text {th }}$ strongest sporting association in Germany with over 640.000 members(6). In two different reviews assessing the relationships between golf, health and physical activity $(\mathrm{PA})(7,8)$ both come to the conclusion, that golf should be recommended to meet PA recommendations. The results of PA intensity of playing golf for men range from 2.8 to 5.3 Metabolic Equivalent of Task (MET). A reason for the wide range of PA intensity might be the fact, that only Basset and colleagues(9) and Dobrosielski et al.(10) measured overall $\mathrm{O}_{2}$-uptake via gas exchange measurements on the course. Other studies calculated the METs used during golf mostly via heartrate (HR)(11-14). Additionally there are studies reporting health benefits from playing golf $(11,12,15)$., but golf is yet to be evaluated in regard to the guidelines given by the ACSM. Broman et al.(15) come to the conclusion that there are age differences in exercise intensity when walking an 18-hole golf course, despite similar perceived exertion throughout the age groups. Bassett et al. evaluated a cohort with a very inhomogeneous age distribution for only 10 minutes and did not give information on playing strength (handicap, hcp), thus the results might not be transferrable to various handicap groups. Taking into account that golf is becoming more popular and the prevalence for inactivity and its resulting pathologies is growing, more accurate data on the possible positive effects of golf in regard to cardiorespiratory health is needed. Therefor we conducted this study investigating two groups of golfers with different skill levels and different age to assess metabolic demands on the golf course, as well as during practice on the driving range. We then calculated the METs using the $\mathrm{O}_{2}$-uptake $\left(\mathrm{VO}_{2}\right)$ for practice and playing golf for the groups with low and high handicaps and compared the results to physical activity guidelines.

\section{Methods}

\section{Subjects}

20 healthy amateur players from German golf clubs were asked to participate in this study. Two groups with 10 golfers each and different skill levels (handicap) were recruited for the study. We formed one group with handicap (Hcp) below 11.5 (LOW) and one group with handicap between 18.5 and $26.4(\mathrm{HIGH})$. Baseline data and subjects characteristics are shown in table 1. All subjects were enlightened about benefits and risks regarding all study procedures. The study was approved by the local ethics committee of the Medical School Hannover and all subjects gave their informed written consent beforehand of any procedures. No subjects under age of 18 years were included in the study.

Table 1: Anthropometric data of included subjects at baseline. 


\begin{tabular}{|lllll|}
\hline & All subjects & Group Hcp low & Group Hcp high & p-value \\
\hline Subjects $(\mathrm{n})$ & 20 & 10 & 10 & \\
\hline Age (years) & $33.0 \pm 9.4$ & $25.9 \pm 5.8$ & $40.1 \pm 6.3$ & $<0.001$ \\
\hline Handicap & $12.7 \pm 10.3$ & $2.9 \pm 2.7$ & $22.5 \pm 2.4$ & $<0.001$ \\
\hline Golf experience (years) & $12.7 \pm 5.8$ & $12.1 \pm 5.2$ & $4.9 \pm 3.8$ & 0.002 \\
\hline Weight $(\mathrm{kg})$ & $82.9 \pm 7.7$ & $80.1 \pm 6.9$ & $85.8 \pm 7.7$ & 0.098 \\
\hline Height $(\mathrm{cm})$ & $183.4 \pm 6.7$ & $182.6 \pm 6.0$ & $184.2 \pm 7.6$ & 0.596 \\
\hline Body mass index & $24.7 \pm 2.2$ & $24.1 \pm 2.3$ & $25.3 \pm 1.9$ & 0.211 \\
\hline
\end{tabular}

\section{Exercise Testing}

The participants performed a graded exercise test (GXT), a driving range training program and played 9 holes of golf under the official rules of golf conducted by the Royal and Ancient Golf Club of St. Andrews. The testing sessions were held on three different days for each subject.

The GXT was carried out on a stationary bicycle ergometer (Ergoline 150P, Bitz, Germany) to test for $\mathrm{VO}_{2 \text { peak }}$ and maximum power $\left(\mathrm{P}_{\max }\right)$. $\mathrm{VO}_{2 \text { peak }}$ was documented as the highest mean of one minute oxygen uptake. The GXT started at 50W with a $16.66 \mathrm{~W}$ increase every minute. Gas exchange (breath-by-breath, MasterScreen CPx Carefusion, Höchberg, Germany) and an electrocardiogram were assessed continuously. Blood pressure and blood lactate concentration (lac) were assessed every 3 minutes during the GXT. Capillary blood samples for lac measurements were drawn from a hyperaemized ear lobe and immediately analyzed using a Biosen C-line (EKF Diagnostics GmbH, Barleben).

\section{Golf Exercise/ Playing Session}

The driving range program included 5 shots with each of a total of five predefined golf clubs. All subjects used the same order of clubs. Just as the common routine in golf training the order started from irons (9, 7 and 5) to long clubs ( 3 wood and driver). Each stroke of one club was made within 30 seconds. The pause in between clubs was 2 min. All subjects used their own clubs.

For the round of 9 holes (Front nine, Golf Club Hannover e. V., Garbsen, Germany) the participants played under the terms of competition in the Stableford format. The slope of the golf course is 142 and its course rating is 73.4 with par 72 calculated for playing the front nine twice. The topography of the golf course is rather flat with the lowest point at $43 \mathrm{~m}$ above sea level and highest point at $54 \mathrm{~m}$ above sea level, walking $28 \mathrm{~m}$ up- and downwards and a distance of $4.2 \mathrm{~km}$ on the front nine in total. Participants walked the course and used a 3-wheel push trolley for their golf bags. All subjects were allowed to use a laser rangefinder to measure distances. Except for scoring no caddies or help from other persons was allowed during the golf round.

Gas exchange data and heartrate was continuously captured during the golf exercise session and the 9-hole competition round using an Oxicon mobile device (breath-by-breath, Carefusion, Höchberg, Germany) and a Polar T31 chest strap (Polar Electro, Kempele, Finland). After the measurement we calculated means of $\% \mathrm{VO}_{2}, \% \mathrm{HR}$ and METs for the 9 holes of competitive golf and the exercise on the driving range. The results were put into relation to the categories for estimating intensity of cardiovascular exercise as seen in table 2 which were adapted according to the guidelines from the American College of Sports Medicine (ACSM)(3).

Table 2: HRmax, maximum heartrate; $\mathrm{VO}_{2 \text { peak, }}$ peak oxygen consumption; $\mathrm{MET}$, metabolic equivalent of task; adapted from(3).

\begin{tabular}{|lllll|}
\hline \multicolumn{4}{l}{ Relative Intensity } & \multicolumn{2}{l|}{ Absolute Intensity (MET) by Age } \\
\hline Intensity & $\% \mathrm{HR}_{\max }$ & $\%^{2} \mathrm{VO}_{2 \text { peak }}$ & Young $(20-39 \mathrm{yrs})$ & Middle Age $(40-46 \mathrm{yrs})$ \\
\hline Very Light & $<57$ & $<37$ & $<2.4$ & $<2.0$ \\
\hline Light & $57-64$ & $37-45$ & $<4.8$ & $<4.0$ \\
\hline Moderate & $64-76$ & $46-64$ & $4.8-7.2$ & $4.0-6.0$ \\
\hline Vigorous & $76-96$ & $64-91$ & $7.2-10.2$ & $6.0-8.5$ \\
\hline
\end{tabular}

Page $3 / 11$ 


\section{Statistics}

Figures and tables contain mean values with standard deviation. All figures containing spirometrical data display 30 s mean values. Statistical significance was set to $\mathrm{p}<0.05$. Statistical significance was tested with a two sided student's T-test for independent samples.

\section{Results}

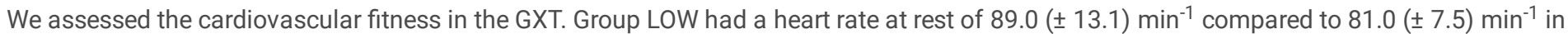
$\mathrm{HIGH}$. The difference in maximum heart rates at completion of GXT between the groups was not significant but $\mathrm{HR}_{\mathrm{max}}$ tended to be higher in group LOW $192.4 \pm 10.4 \mathrm{~min}^{-1}$ versus $182.6 \pm 12.8 \mathrm{~min}^{-1}$ in group $\mathrm{HIGH}(\mathrm{p}=0.077)$. No tendencies or significant differences were seen in $\mathrm{VO}_{2 \mathrm{peak}}$ $\mathrm{RER}_{\max }$ or $\mathrm{HR}_{\max }($ table 3$)$.

Table 3: Comparison of parameters from the initial graded exercise test (GXT).

\begin{tabular}{|c|c|c|c|c|}
\hline & All subjects & Group Hcp low & Group Hcp high & p-value \\
\hline Power $_{\max } \mathrm{GXT}(\mathrm{W})$ & $260.0 \pm 28.9$ & $248.7 \pm 19.9$ & $270.4 \pm 33.2$ & 0.093 \\
\hline Heartrate $_{\max } \mathrm{GXT}\left(\min ^{-1}\right)$ & $187.5 \pm 12.5$ & $192.4 \pm 10.4$ & $182.6 \pm 12.8$ & 0.077 \\
\hline Heartrate $_{\text {rest }}$ GXT $\left(\mathrm{min}^{-1}\right)$ & $84.8 \pm 11.2$ & $88.8 \pm 13.1$ & $80.8 \pm 7.5$ & 0.114 \\
\hline $\mathrm{VO}_{\text {peak }} \mathrm{GXT}(\mathrm{ml} / \mathrm{min} / \mathrm{kgBW})$ & $38.1 \pm 5.9$ & $39.2 \pm 6.0$ & $37.2 \pm 5.9$ & 0.463 \\
\hline VO2 $2_{\text {peak }}$ GXT (I/min) & $3.21 \pm 4.2$ & $3.22 \pm 3.8$ & $3.20 \pm 4.8$ & 0.907 \\
\hline $\mathrm{RER}_{\max } \mathrm{GXT}$ & $1.4 \pm 0.1$ & $1.3 \pm 0.1$ & $1.4 \pm 0.1$ & 0.113 \\
\hline lactate $_{\max } \mathrm{GXT}$ & $9.6 \pm 1.5$ & $9.3 \pm 1.5$ & $10.0 \pm 1.6$ & 0.288 \\
\hline
\end{tabular}

The difference in absolute $P_{\max }$ between the two groups was not significant, yet group LOW tended to have a lower $P_{\text {max }}$ in the GXT than group HIGH (table 3). However, this tendency was not apparent in relative $\mathrm{P}_{\max }$. With RER above $1.3, \mathrm{HR}_{\max }$ over $180 \mathrm{~min}^{-1}$ and lac over $9.3 \mathrm{mmol} / \mathrm{I}$ (table2) both groups reached the physical exhaustion at completion of the GXT.

During the driving range exercise subjects had an average oxygen consumption (Fig. 1) of $13.2 \pm 2.3 \mathrm{ml} / \mathrm{min} / \mathrm{kgBW}$ in LOW and $13.4 \pm 2.3$ $\mathrm{ml} / \mathrm{min} / \mathrm{kgBW}$ in $\mathrm{HIGH}$. This results in exercise intensities (as proportion of $\mathrm{VO}_{2 \text { peak }}$ ) of $34.2 \pm 6.5 \%$ in $\mathrm{LOW}$ and $36.4 \pm 6.5 \%$ in $\mathrm{HIGH}$. Both the differences between LOW and $\mathrm{HIGH}$ in $\% \mathrm{VO}_{2 \text { peak }}(\mathrm{p}=0.435)$ and $\mathrm{VO}_{2}(\mathrm{p}=0.881)$ were not significant. Accordingly, there were no differences between the groups on the DR in METs $(p=0.879), \% \mathrm{HR}_{\max }(p=0.920)$ and HR $(p=0.402)$.

Playing the 9 holes of golf the 02-uptake average was $18.0 \pm 1.7 \mathrm{ml} / \mathrm{min} / \mathrm{kgBW}$ in LOW and $17.4 \pm 2.7 \mathrm{ml} / \mathrm{min} / \mathrm{kgBW}$ in $\mathrm{HIGH}(\mathrm{p}=0.596)$.

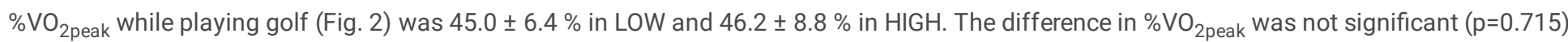
between the two groups. Mean METs (Fig. 3) during the 9 holes of golf were not significantly ( $p=0.596)$ different between groups LOW (5.13 \pm 0.49) and HIGH (4.98 \pm 0.77). LOW needed $64.4 \pm 7.0 \%$ and HIGH $61.6 \pm 3.6 \%$ of their maximum heartrate of the GXT (\%HR max $)$ to complete the 9-holes competition. The difference in HR during the 9 hole course between LOW $\left(123.9 \pm 12.9 \mathrm{~min}^{-1}\right)$ and HIGH $\left(112.5 \pm 10.3 \mathrm{~min}^{-1}\right)$ was significant with $\mathrm{p}=0.043$. The difference (LOW, $98 \pm 19 \mathrm{~min} ; \mathrm{HIGH}, 103 \pm 14 \mathrm{~min}$ ) between the groups in playing time was not significantly different $(p=0.523)$.

Compared to the DR practice session the $\mathrm{O}_{2}$-uptake on the 9-hole golf course was significantly higher in both groups (LOW, $\mathrm{p}<0.001$; $\mathrm{HIGH}$, $\mathrm{p}=0.001)$, as well as the $\% \mathrm{VO}_{2 \text { peak }}(\mathrm{LOW}, \mathrm{p}<0.001 ; \mathrm{HIGH}, \mathrm{p}=0.002)$ and the METs (LOW, $\left.\mathrm{p}<0.001 ; \mathrm{HIGH}, \mathrm{p}=0.001\right)$. The differences in HR (LOW, $\mathrm{p}=0.029 ; \mathrm{HIGH}, \mathrm{p}=0.175$ ) and \% $\mathrm{HR}_{\max }$ (table2, LOW, $\mathrm{p}=0.006 ; \mathrm{HIGH}, \mathrm{p}=0.123$ ) were only significant in the LOW group and not in the HIGH group when comparing DR and the 9-hole competition round. 
Compared to ACSM guidelines and recommendations for cardiorespiratory exercise [3] the exercises on the driving range did not reach the given values for "moderate" in both groups. During the 9-hole competition mean METs were $4.98 \pm 0.77$ for HIGH and $5.13 \pm 0.49$ for LOW (Fig. 3 ). There were no significant differences between HIGH and LOW for the time spent in the very light $(p=0.615)$, light $(p=0.995)$, moderate $(p=0.476)$ or vigorous ( $p=0.132)$ category for METs. Fig. 3 displays the mean minutes spent in the different activity categories during competition (very light, $6.0 \pm 5.8 \mathrm{~min}$; light $25.0 \pm 17.8 \mathrm{~min}$; moderate $46.3 \pm 16.4 \mathrm{~min}$; vigorous $12.8 \pm 12.5 \mathrm{~min}$ ) and DR exercise (very light, $4.0 \pm 2.3 \mathrm{~min}$; light $18.5 \pm 3.8 \mathrm{~min}$; moderate $3.0 \pm 3.3 \mathrm{~min}$ ) for all subjects.

\section{Discussion}

With this study we compared two groups with different age and skill level in their metabolic response during playing and practicing golf. The two groups showed neither during practice nor during playing golf significant differences in $\mathrm{METs}$ and $\% \mathrm{VO}_{2}$. Both groups reached moderate intensity with $\mathrm{METs}$ and $\% \mathrm{VO}_{2}$ according to the ACSM guidelines on the golf course but not on the driving range(3). The second important finding is that both groups spent about half the time during playing 9 holes of golf in the "moderate" intensity category according to ACSM. This time alone adds about 45 minutes (out of 90 min played) to the PA activity of the golfers.

Compared to the literature $(9,10,16)$ the METs in this study were higher, despite the fact that the 9 holes were played on a fairly flat course and the use of a push or pull trolley. Only Hendelman et al.(17) and the Compendium of physical activities(16) present comparable values on METs. Notably one would expect the younger and more skilled group to have lower $\mathrm{METs}$ than an older group. Instead the results in $\mathrm{METs}$ and $\% \mathrm{O}_{2}$ were not significantly different. Contrary to our results a higher intensity for older golfers was found by Broman et al. (18), stating that the younger golfers energy demand is not as high. This is interesting because there was no difference in perceived exertion between the three different age groups in the study of Broman et al(15). A reason for this difference might be the lack of a direct measurement of VO2 by Broman and colleagues, since they calculated 02-uptake using the HR during playing golf. Oxygen uptake on the golf course was only measured by Bassett et al.(9) and Dobrosielsky et al.(10). Both studies did find comparable results to ours regarding METs and 02-uptake.

As mentioned in the introduction golf is a wide spread recreational sport with the advantageous feature that it can be played by almost all age classes with or without diseases and even orthopedic problems. If one looks at time spent in the activity categories, the combination and proportions of light, moderate and vigorous are very advantageous for providing a substantial benefit for physical health. Even more so that golf is usually played for at least 90 to 120 min for 9 holes. Thus golf provides a very motivational and sufficient strenuous sport to elicit improvements to physical conditioning for a wide variety of participants. Additionally, the usual golfer routine to practice on the driving range beforehand of playing on the course, seems to provide an optimal warm-up in regard of the measured physical intensity in this study.

Compared to the energy demand on the course, energy expenditure on the driving range was significantly lower in both groups. With the differences in METs and \% $\mathrm{VO}_{2}$ not being significant on the DR and on the course we conclude that for our two groups, age and skill level does not have a significant impact on the metabolic demand of golf. In regard to METs and $\% \mathrm{VO}_{2}$ practicing golf on the DR does fall into the "light intensity" category following the ACSM(3) guidelines. As seen in figure 4 the oxygen uptake does rise with repeating golf swings. The pause of 2 $\mathrm{min}$ in between the 5 stroke sets with each club is sufficient to recover almost to a resting $\mathrm{VO}_{2}$. With a smaller pause between the sets the metabolic demand on the driving range might also rise to a "moderate" intensity with ongoing time. Although no significant difference in oxygen uptake can be seen for different clubs, oxygen uptake tends to get higher for long club. Reason behind that can be the higher swing and head speed of a driver due to its lighter weight and longer shaft. A reason for the rise in $\mathrm{VO}_{2}$ might be the repetition of the golf swings within a set of shots. A golf stroke is a short, but a highly intense movement. With every part of the body involved and the respected muscles activated throughout a single golf stroke(19), it seems logical that the energy demand, the strain and thus the oxygen consumption grow with repeating golf swings. Since the exercise on the DR lasted only $25 \mathrm{~min}$, the oxygen uptake should further rise with time and ongoing exercise. Further studies might evaluate the training effect of a longer exercise session on the DR, especially since we could not find any other studies evaluating golf exercise in this regard.

Although the difference in \%HR was not significant between groups, interestingly the "moderate" intensity for \%HR was only reached by LOW, which is the younger and fitter group compared to the HIGH group. Additionally LOW had a significant higher HR on course compared to HIGH. A reason could be a higher walking speed, since the heartrate and energy demand is influenced by the walking pace during playing golf(16, 20). The time between golf shots is quite large and the strain from the golf shot on the cardiovascular system is short. Thus the sympathetic activation caused by a single golf stroke through adrenalin is low. There was no significant difference between the groups in playing time for the 9 holes competition, but the standard deviation for playing time was high, which might disguise some differences in this result. The heartrates in this study are comparable with other studies $(10,18,21,22)$ for the HIGH group. Our LOW group had a higher HR compared to the literature. Two reasons have to be considered to not overestimate this result. First, the LOW group was significantly younger. With ongoing age the heartrate tends to decline $(23,24)$. Secondly, the LOW group tended to have a higher maximum HR in the GXT too. Although the difference in HR max 
missed out on significance, the mean difference of 10 beats per minute can also be found in the HR on course. During the exercise on the DR both groups are well below the ACSM "moderate" intensity. Thus a 20 min exercise does only resemble a "light" exercise. If we consider that for a golfer a standard routine would be a warmup of at least 20 min on the driving range and subsequently a round of 9 or 18 holes of golf, this would match a near perfect moderate endurance exercise. The fairly low to moderate intensity for an exercise time of at least two hours is more than adequate to elicit improvements in endurance performance and improvements in cardiovascular health.

\section{Conclusion}

In summary the metabolic demands on course were higher compared to exercising on the driving range independently of the group and thus independently of skill level and age. Exercising on the driving range did fulfill the conditions of "light" intensity according to ACSM guidelines in $\% \mathrm{HR}, \% \mathrm{VO}_{2}$ and METs. Whereas playing golf under tournament conditions the results of $\% \mathrm{HR}, \mathrm{METs}$ and $\% \mathrm{VO}_{2} \mathrm{were}$ unanimous in the same category. For METs both groups were well above the low cut off for "moderate". For $\% \mathrm{VO}_{2}$ the HIGH group reached the "moderate" intensity and the LOW group fell just short of it. For \%HR it is turned around, with LOW reaching the "moderate" category whereas HIGH does not. However, we recommended golf as an effective means for endurance exercise with a moderate intensity. Especially when one considers that a golfer spends half of the time of playing a golf course in the "moderate" intensity category, and an average golf round of 9-holes lasts $90-120$ min, with 18 holes lasting twice as long. We feel that the motivation and physical possibility for untrained or recreationally trained people to exercise at a moderate intensity for more than 90 min would be lower in standard sports like running, walking, cycling or swimming. It seems that for golf can serve as an activity to improve cardiovascular health for young and, as well as for low and high handicappers.

\section{Abbreviations}

WHO = World Health Organization

ACSM = American College of Sports Medicine

DGV = German Golf Association

PA = Physical Activity

MET = Metabolic Equivalent of Task

$\mathrm{HR}=$ heartrate

Hcp = Handicap (golf skill level)

$\mathrm{VO}_{2}=$ oxygen-uptake

GXT = graded exercise test

$P_{\text {max }}=$ Maximum power from graded exercise test

RER $=$ Respiratory exchange ratio

$\mathrm{BW}=$ Bodyweight

\section{Declarations}

\section{Acknowledgements}

We acknowledge support by the German Research Foundation (DFG) and the Open Access Publication Fund of Hannover Medical School $(\mathrm{MHH})$.

\section{Ethical Approval and Consent to participate}

All subjects were informed about possible benefits and risks regarding all study procedures.

All study procedures were approved by the local ethics committee of the Hannover Medical School and all subjects gave their informed written consent of participation before any study procedures.

\section{Consent for publication}


not applicable

\section{Availability of data and materials}

The datasets used and analyzed during the current study are available from the corresponding author on reasonable request.

\section{Competing interests}

The authors declare that they have no competing interests

\section{Funding}

Not applicable

\section{Authors' contributions}

JE was the major contributor in writing the article, JE, CK, UT contributed to study design and protocol, JE, US, TR contributed to data aquisition and analysis, UT, CK contributed to drafting and revising the manuscript

\section{Acknowledgements}

We acknowledge support by the German Research Foundation (DFG) and the Open Access Publication Fund of Hannover Medical School $(\mathrm{MHH})$.

\section{Author's Information}

Not applicable

\section{Literature}

1. Hallal PC, Andersen LB, Bull FC, et al. Global physical activity levels: Surveillance progress, pitfalls, and prospects. Lancet. 2012;380(9838):247-57.

2. World Health Organization. Global recommendations on physical activity for health. Geneva World Heal Organ. 2011; Available from: http://www.who.int/dietphysicalactivity/factsheet_recommendations/en/.

3. Pescatello LS, Arena R, Riebe D, Thompsen PD, editors. ACSM's Guidelines for Exercise Testing and Prescription. 9th Editio. Wolters Kluwer Health, Lippincott Williams \& Wilkins; 2014. $482 \mathrm{p}$

4. World Health Organization. Global Recommendations on Physical Activity for Health. Geneva: WHO Library Cataloguing-in-Publication Data; 2010. 60 p. Available from: https://apps.who.int/iris/bitstream/handle/10665/44399/9789241599979_eng.pdf;jsessionid=9F65F3C48081DAB6D2B17CCBDBAB800E? sequence $=1$.

5. Pfeifer K, Banzer W, Ferrari N, et al. National Recommendations for Physical Activity and Physical Activity Promotion. Erlangen: FAU University Press; 2016. 130 p. Available from: https://opus4.kobv.de/opus4-fau/files/7827/Bewegungsempfehlung_OPUS.pdf.

6. General Golf Statistics. Ger Golf Assoc. 2019;10. [cited 2020 May 14] Available from: https://serviceportal.dgvintranet.de/files/pdf1/dgv_statistiken_2019_gesamt_internet.pdf.

7. Murray AD, Daines L, Archibald D, et al. The relationships between golf and health: A scoping review. Br J Sports Med. 2017;51(1):12-9.

8. Luscombe J, Murray AD, Jenkins E, Archibald D. A rapid review to identify physical activity accrued while playing golf. $B M J$ Open. 2017;7(11):1-9.

9. Bassett J, Ainsworth BE, Swartz AM, Strath SJ, O'Brien WL, King GA. Validity of four motion sensors in measuring moderate intensity physical activity. Med Sci Sports Exerc. 2000;32(9 SUPPL.):471-80.

10. Dobrosielski DA, Brubaker PH, Berry MJ, Ayabe M, Miller HS. The Metabolic Demand of Golf in Patients With Heart Disease and in Healthy Adults. J Cardiopulm Rehabil Prev. 2002;22(2):96-104.

11. Unverdorben M, Kolb M, Bauer I, et al. Cardiovascular load of competitive golf in cardiac patients and healthy controls. Med Sci Sports Exerc. 2000;32(10):1674-8.

12. Palank EA, Hargreaves EH. The benefits of walking the golf course: Effects on lipoprotein levels and risk ratios. Phys Sportsmed. 1990;18(10):77-80.

13. Tangen JO, Sunde A, Sageie J, et al. In Accordance with Governmental Recommendations-A Study of Golf and Health. 2013;1:15-25. 
14. Zunzer SC, von Duvillard SP, Tschakert G, Mangus B, Hofmann P. Energy expenditure and sex differences of golf playing. J Sports Sci. 2013;31(10):1045-53

15. Broman G, Johnsson L, Kaijser L. Golf: A high intensity interval activity for elderly men. Aging Clin Exp Res. 2004;16(5):375-81.

16. Ainsworth BE, Haskell WL, Whitt MC, et al. Compendium of physical activities: an update of activity codes and MET intensities. Med Sci Sports Exerc. 2000;32(9 Suppl):S498-504.

17. Hendelman D, Miller K, Baggett C, Debold E, Freedson P. Validity of accelerometry for the assessment of moderate intensity physical activity in the field. Med Sci Sports Exerc. 2000;32(9):S442-9.

18. Broman G, Johnsson L, Kaijser L. Golf: a high intensity interval activity for elderly men. Aging Clin Exp Res. 2004;16:375-81.

19. McHardy A, Pollard H. Muscle activity during the golf swing. Br J Sports Med. 2005;39(11):799-804.

20. Parkkari J, Natri A, Kannus P, et al. A controlled trial of the health benefits of regular walking on a golf course. Am J Med. 2000;109(2):1028.

21. Murase Y, Kamei S, Hoshikawa T. Heart rate and metabolic responses to participation in golf. J Sports Med Phys Fitness. 1989;29(3):269272.

22. Ikeda ER, Cooper L, Gulick P, Nguyen P. The metablic cost of carrying a single- versus double-strap- golf bag. J Strength Cond Res. 2008;22(3):974-7.

23. Fleg JL. Alterations in Cardiovascular Structure and Function with Advancing Age. Am J Cardiol. 1986;57:33C-44C.

24. Brandfonbrener M, Landowne M, Shock NW. Changes in cardiac output with Age. Circulation. 1955;12(October):557-66.

\section{Figures}

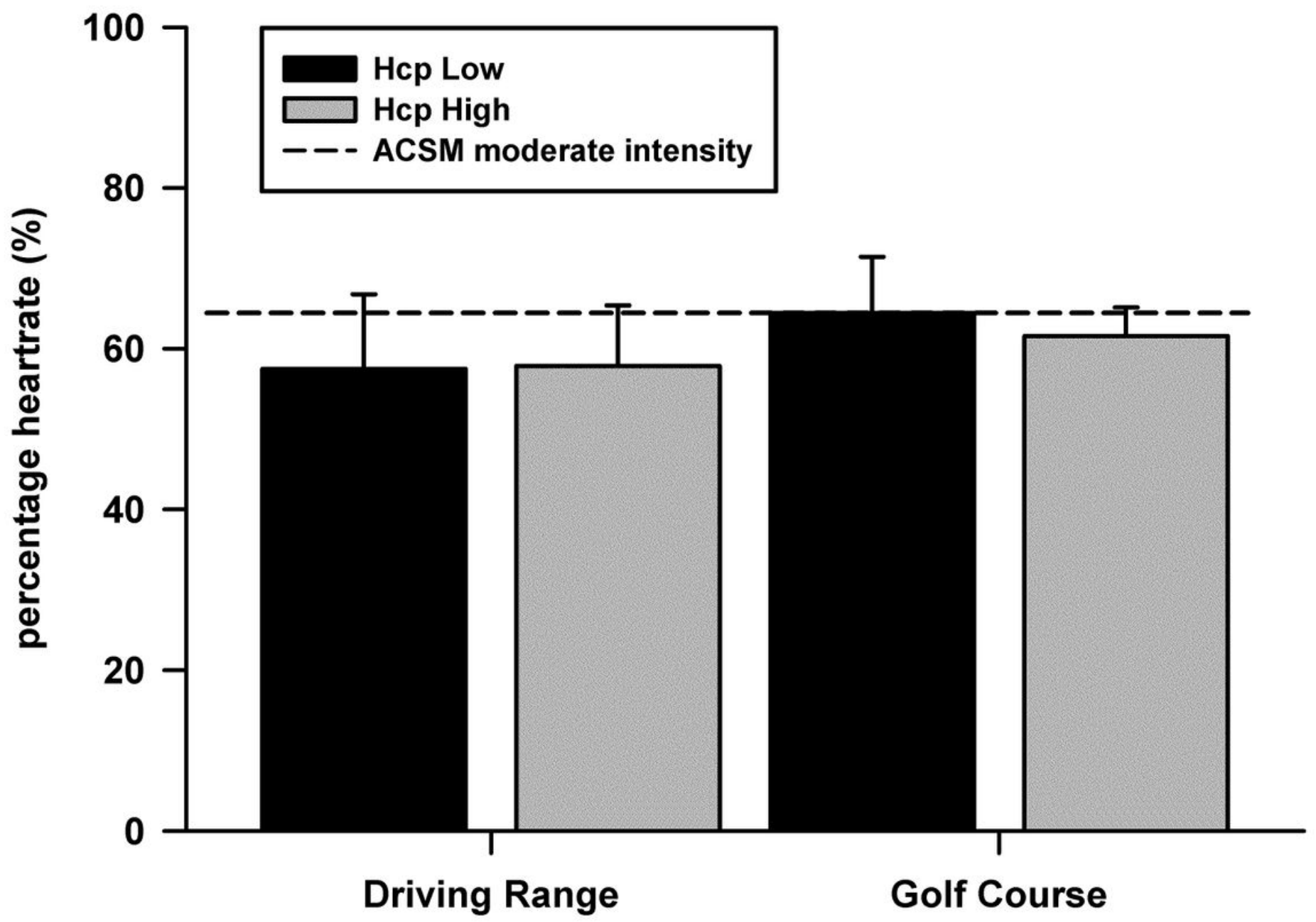


Figure 1

Comparison of percentage of maximum heartrate (\%HRmax) during driving range exercise session and playing 9 holes between low and high handicap groups. Dashed line marks ACSM recommendation for moderate intensity.

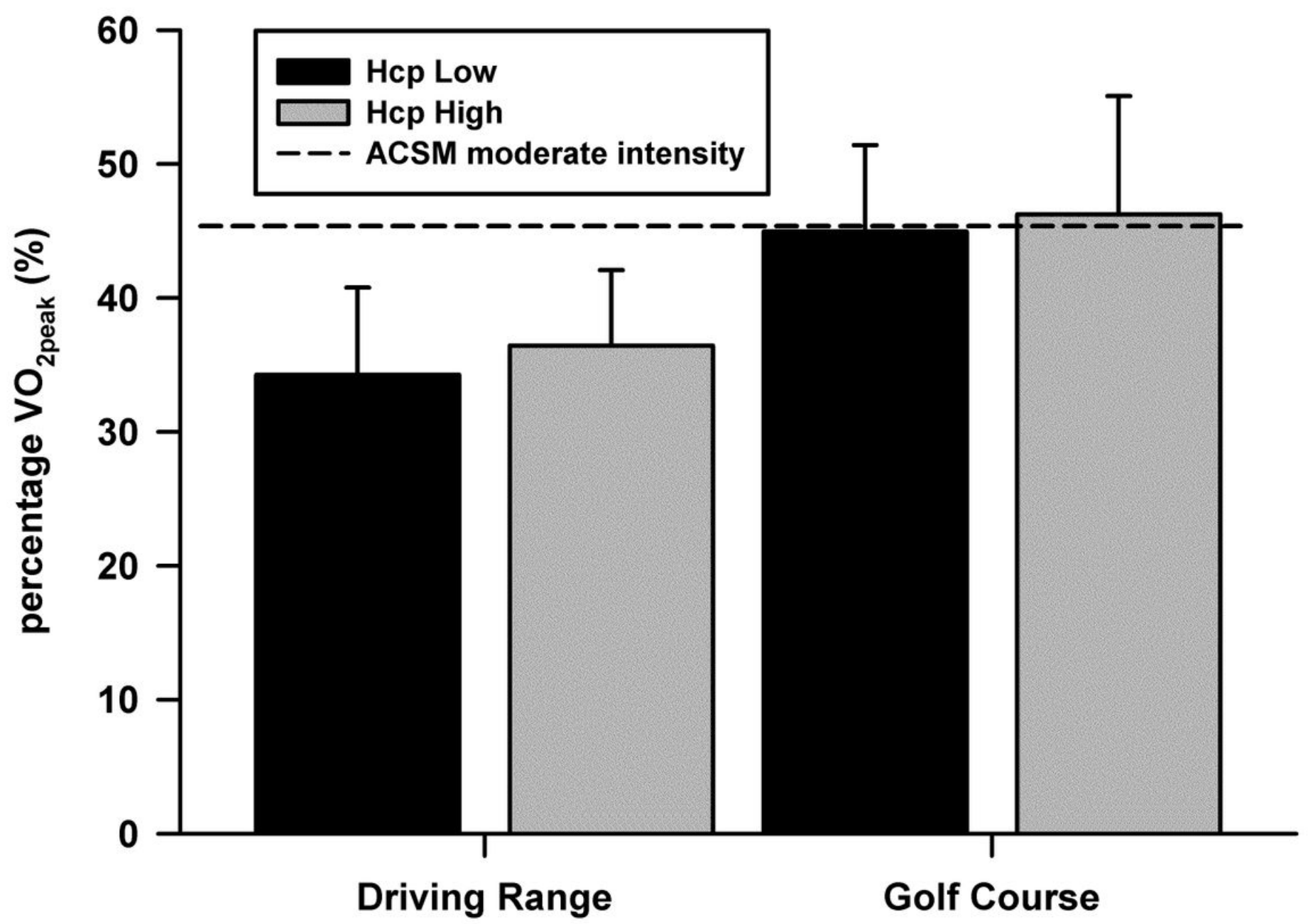

Figure 2

Comparison of percentage of peak 02-uptake (\%VO2peak) during driving range exercise session and playing 9 holes between low and high handicap groups. Dashed line marks ACSM recommendation for moderate intensity. 

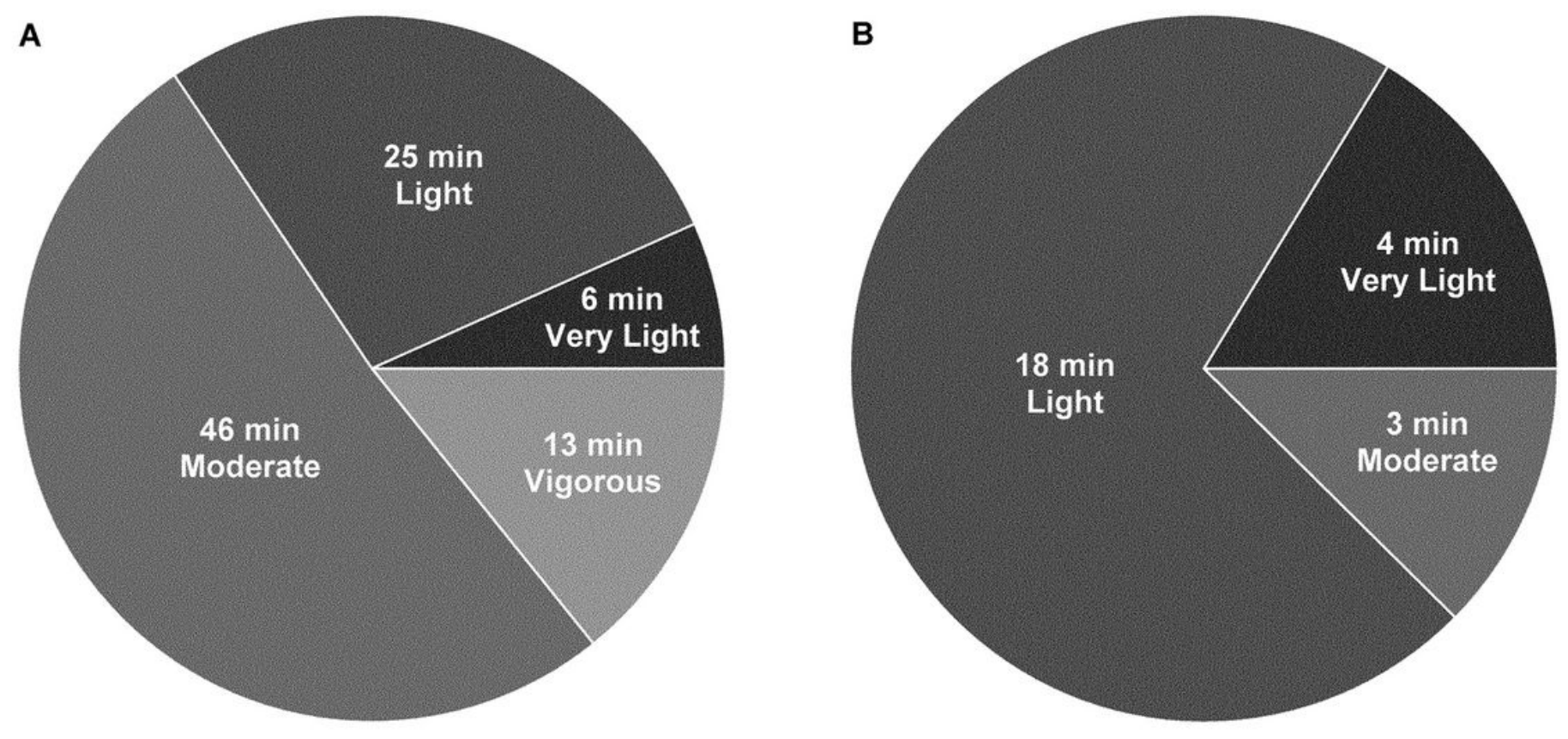

Figure 3

Comparison of the time spent in the different ACSM activity categories during A) 9-hole competition and B) DR exercise. 


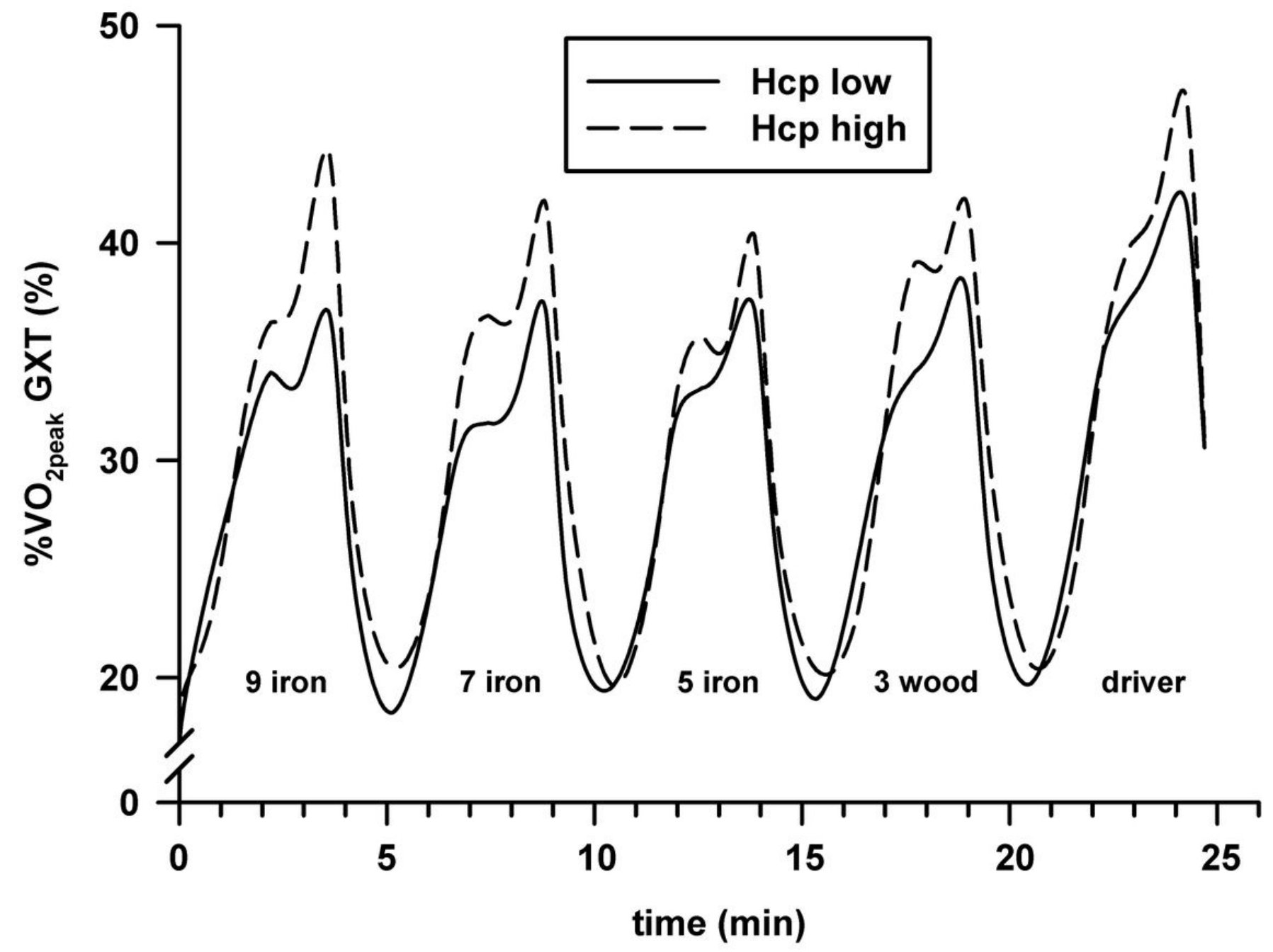

Figure 4

Comparison of the proportional oxygen uptake (\%VO2peak) between groups LOW and HIGH of the proportional oxygen uptake (\%VO2peak) during golf exercise. Hcp, handicap. 